\title{
SHORT-TERM VARIATIONS IN STRAIN AND SURFACE TILT ON STORGLACIÄREN, KEBNEKAISE, NORTHERN SWEDEN*
}

\author{
By Peter JANSSON and Roger LeB. HoOKe ${ }^{\dagger}$
}

(Naturgeografiska Institutionen, Stockholms Universitet, S-106 91 Stockholm, Sweden)

AbStract. Tiltmeters that can detect changes in slope of a glacier surface as small as $0.1 \mu$ rad have been used on Storglaciären. The records obtained to date have been from the upper part of the ablation area, where the bed of the glacier is overdeepened. A total of $82 \mathrm{~d}$ of records has been obtained for various time periods between early June and early September.

There is generally a gradual change in inclination of the glacier surface over periods of several days, but these changes do not appear to be systematic. In particular, they are not consistent with vertical movements of stakes located 2-3 ice thicknesses away from the tiltmeters. This suggests that the tiltmeters are sensing disturbances over areas with diameters comparable to the local ice thickness.

Superimposed on these trends are diurnal signals suggesting rises and falls of the surface just up-glacier from the riegel that bounds the overdeepening on its downglacier end. These may be due to waves of high water pressure originating in a crevassed area near the equilibrium line. If this interpretation is correct, the waves apparently move down-glacier at speeds of $\sim 20-60 \mathrm{~m} \mathrm{~h}^{-1}$, and become sufficiently focused, either by the bed topography or by conduit constrictions, to result in local uplift of the surface. Also observed are abrupt tilts towards the glacier center line shortly after the beginning of heavy rainstorms. These appear to be due to longitudinal stretching as the part of the glacier below the riegel accelerates faster than that above. Water entering the glacier by way of a series of crevasses over the riegel is believed to be responsible for this differential acceleration. In June 1987, a dramatic event was registered, probably reflecting the initial summer acceleration of the glacier.

\section{INTRODUCTION}

Storglaciären (Fig. 1) is a small valley glacier, situated in the Kebnekaise massif of northern Sweden, which has been studied in some detail since 1945 when Schytt (1959, $1966,1968)$ began the still-continuing mass-balance measurements on it. Since 1981, detailed measurements of the surface-velocity field have been undertaken (Hooke and others, 1983, 1989), supplemented by studies of water pressure in bore holes and moulins (Holmlund and Hooke, 1983), measurements of bore-hole deformation (Hooke and others, 1987; paper in preparation by V. Pohjola and R. LeB. Hooke), studies of water balance (Östling and Hooke, 1986), dye-trace experiments (Hooke and others, 1988; Seaberg and others, 1988), and highly sensitive strain and tilt measurements. The present paper describes the latter.

* Publication No. 1114 of the School of Earth Sciences, Department of Geology and Geophysics, University of Minnesota, Minneapolis, Minnesota 55455, U.S.A.

Permanent address: Department of Geology and Geophysics, University of Minnesota, Minneapolis, Minnesota 55455, U.S.A.
Slightly below the middle of the ablation area on Storglaciären, a transverse bedrock ridge, or riegel (Fig. 1), forces the basal ice to flow $\sim 60 \mathrm{~m}$ up-hill from its maximum depth of $250 \mathrm{~m}$ (Björnsson, 1981). Due to this constriction, longitudinal strain-rates, which are compressive throughout most of this overdeepening, gradually increase toward the riegel (to satisfy continuity), becoming extending over its crest. In at least one part of this overdeepening, electrical resistivity measurements strongly suggest that the glacier is underlain by a layer of till, $\sim 0.4-0.7 \mathrm{~m}$ thick (Brand and others, 1987). Tracer studies provide some basis for believing that this till layer underlies the glacier throughout the overdeepening (Hooke and others, 1988).

Recognition (Holmlund and Hooke, 1983) of phenomena on Storglaciären that are similar to the mini-surges of Variegated Glacier (Kamb and Engelhardt, 1987), a surging glacier in Alaska, provided motivation for the present research effort. Mini-surges involve waves of high water pressure in the subglacial system that propagate downglacier, in the case of Variegated Glacier at speeds of several hundred meters per hour. The wave is accompanied by surface uplift and an increase in surface velocity. Strainrates become abnormally compressive in front of the wave and extending behind it. The comparable events on Storglaciären are less accentuated. However, the subglacial water pressure does rise high enough to equal (or even locally slightly exceed) the overburden pressure and thus lift the glacier. This is accompanied by audible cracking. Extreme strain-rates, 50-100 times the summer average, may occur during these events (Holmlund and Hooke, 1983, p. 23).

Throughout the overdeepening on Storglaciären, water pressures are relatively constant and average $80-90 \%$ of the overburden pressure, whereas, in contrast, water pressures down-glacier from the riegel vary diurnally during fair weather, with peak pressures at about $14.00 \mathrm{~h}$ (Hooke and others, 1987, 1989). Tracer experiments in bore holes indicate that water passing through the overdeepening emerges in Nordjokk (Fig. 1), a stream that normally has a negligible sediment load. Water entering the glacier in moulins over the riegel and passing through or beneath the lower part of the glacier emerges in Sydjokk. The reasons for the remarkable change in "water-table" and drainage character across the riegel are not understood.

Surface velocities in the vicinity of the riegel average $\sim 35 \mathrm{~mm} / \mathrm{d}$, and variations in velocity over the time spans of the water-pressure peaks are too small to be detected with the survey equipment available here. Thus, sensitive strain meters and tiltmeters have been used to study variations at the glacier surface on these time-scales.

\section{EXPERIMENTAL TECHNIQUES}

The strain-meter measurements were conducted in 1983 by L. Lindh. A light-weight wire was run through a $10 \mathrm{~m}$ long, $0.1 \mathrm{~m}$ diameter plastic tube buried $\sim 1 \mathrm{~m}$ below the glacier surface in a well-drained trench. One end of the wire was secured to a steel post frozen into the ice. The other end passed over a pulley fastened to a similar post, and was secured to a weight that held the wire taut. Also 


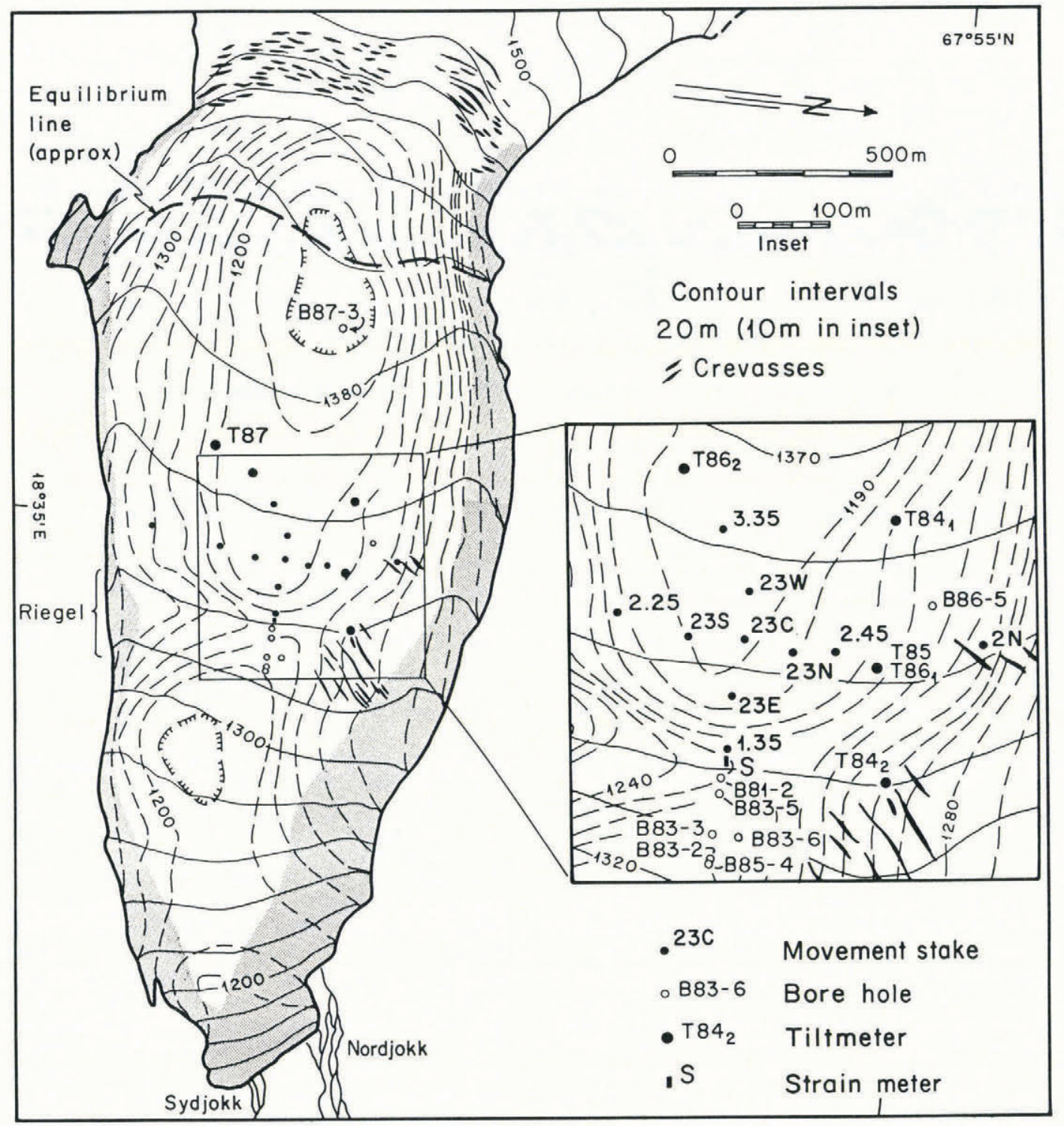

Fig. 1. Map of Storglaciären showing surface and bed topography. The insert shows locations of tiltmeters and the strain meter, of the bore holes and moulins used for water-pressure measurements, and of stakes used for velocity measurements.

fastened to the latter post and to the wire was a flexible stainless-steel strip to which strain gauges had been attached. Movement of the wire relative to this post caused bending of the steel strip, and this bending was sensed by the gauges. After amplification, the signal from the strain gauges was plotted by a chart recorder. The meters were time-consuming to install and melted out rapidly, so the length of record from them is, unfortunately, short.

The tiltmeter studies began in 1984, utilizing two Westphal biaxial tiltmeters, originally designed to record variations in tilt on the surfaces of active volcanoes. The instruments used on Storglaciären were modified to survive the special conditions to be expected on a glacier. They consist of a sensor encapsulated in a waterproof steel cylinder, $0.28 \mathrm{~m}$ high and $0.14 \mathrm{~m}$ in diameter, that is allowed to freeze into the ice at a depth of $\sim 3 \mathrm{~m}$, and an electronic package that is placed at the surface. With the use of switches in the latter, the operator can drive reversible motors that level the sensor inside the steel cylinder once it is frozen into the ice. The electronic package also amplifies the output signal, which is then transmitted to a chart recorder in an instrument hut on the glacier or to a data logger. The instruments are powered by an ordinary $12 \mathrm{~V}$ car battery.

The tiltmeters have a sensitivity of $0.1 \mu \mathrm{rad}$ which corresponds to a differential vertical change of $0.01 \mathrm{~mm}$ in $100 \mathrm{~m}$. These changes are registered in two mutually perpendicular directions. The instruments were installed so that one of these directions coincided approximately with the direction of flow, the other being, therefore, transverse.

Although the tiltmeter studies were started in 1984, results, some of which have been reported earlier (Hooke and others, 1987), have been minimal owing to frequent malfunctions. In 1984, the main culprit was electrical storms that disabled the tiltmeters themselves. During the winter of 1985 , the instruments were modified to protect them against such damage but, in 1985 and again in 1986, the total period of record was also limited by problems, first with a channel changer on a chart recorder that, although new, failed repeatedly, and then later by problems with a new multi-channel chart recorder that proved to be mismatched to the instruments and also sensitive to electrical storms. In 1987, use of a data logger (Campbell Scientific 21X) allowed continuous recordings from 3 June to 14 July.

Temperature data for the time periods of interest in 1985 and 1986 were recorded at Tarfala Station, located $0.5 \mathrm{~km}$ north of the toe of the glacier at an elevation of $1130 \mathrm{~m}$. Precipitation was recorded by a tipping-bucket rain-gauge at the instrument hut. In 1987, temperature and precipitation were recorded on a data logger at a site close to the tiltmeter on the glacier. Water levels in bore holes were monitored with the use of standard 5 or 10 bar automobile oil-pressure gauges connected to a chart recorder or data logger. Finally, vertical and horizontal velocities of a number of stakes were being measured over time intervals of 1 to $\sim 7 \mathrm{~d}$ during the melt season, using standard survey techniques (Hooke and others, 1983, 1989). 


\section{RESULTS}

The strain-meter results are shown in Figure 2, together with water-pressure measurements in some nearby bore holes. After a period of relatively constant but weak stretching, the meters, apparently in response to an increase in amplitude of the diurnal component of the waterpressure variations, also began to show a diurnal variation with extension starting in the early morning and lasting until late evening, followed by compression until the following morning. This pattern cannot be attributed to thermal expansion of the ice, as air temperatures were above freezing during the entire period, and the ice temperature, being unable to rise above $0^{\circ} \mathrm{C}$, could not vary diurnally. Thermal expansion of the wire, due, for example, to penetration of radiation through the ice, would be in the wrong direction to account for the observed pattern.

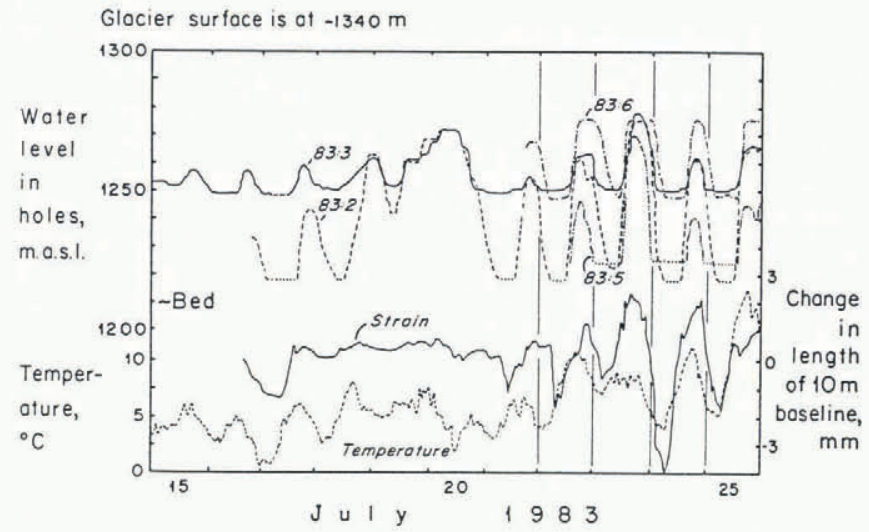

Fig. 2. Strain, expressed as the change in length of a $10 \mathrm{~m}$ base line, and water levels measured simultaneously in bore holes connected to the subglacial hydraulic system.

The strain variations appear to be related to the water-level fluctuations. However, the water-pressure measurements do not reveal the precise time at which the pressure increase began. This is because the transducers in the bore holes were $10-40 \mathrm{~m}$ above the bed, and water levels dropped below them during the night. As the bore holes were somewhat down-glacier from the strain meter, it is logical that increases in water pressure there should result in stretching at the site of the strain meter, so this could well be the cause of the tension. However, if the water causing these increases in pressure was derived locally from surface melt, one would not expect the pressure to increase appreciably before the air temperature had risen significantly from its overnight low.

The period of weak stretching between 17 and 20 July was a time interval during which water pressures were generally higher than normal. The lowest pressure during this time occurred early on $18 \mathrm{July}$; its duration was shorter than normal for this time of day (Fig. 2). These high water pressures were probably a result of storms that yielded 4 , 24.5 , and $23.5 \mathrm{~mm}$ of rain on 18, 19, and 20 July, respectively. We infer that water pressures during these 4 days were never low enough for a sufficiently long period of time to result in compression at the site of the strain

The tiltmeters, as a result of the various problems described above, yielded only $6 \mathrm{~d}$ of useful recordings in 1984 (Hooke and others, 1987), $7 \mathrm{~d}$ in 1985, and $27 \mathrm{~d}$ in 1986. In 1987, a continuous $42 \mathrm{~d}$ record was obtained during 3 June to 14 July.

The 1984 data have already been published. Thus, here we reproduce only the last part of these records (Fig. 3) Of particular interest are the diurnal variations which reflect a relative rise of the center of the glacier about mid-day, and an associated increase and subsequent decrease in longitudinal slope. These variations are superimposed on a longer-term trend of decreasing longitudinal and transverse slopes.

The 1985 tiltmeter data can be divided into two types: a diurnal pattern for days with normal water input to the glacier and a "direct-response" pattern when intense rainfall
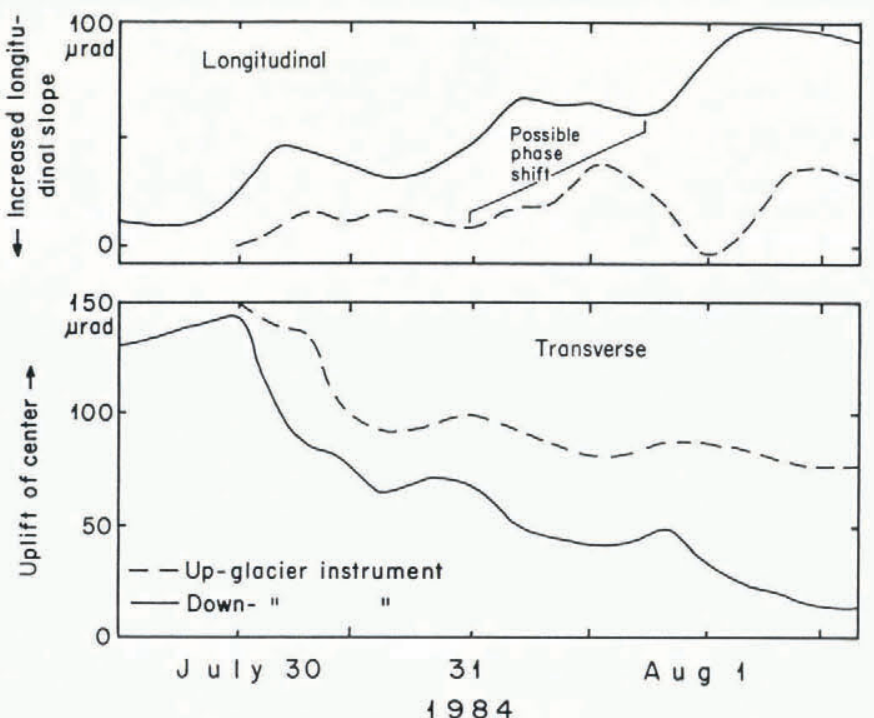

Fig. 3. Records from tiltmeters at sites $T 84_{1}$ and $T 84_{2}$ (Fig. 1) from 29 July through I August 1984.

overshadowed the diurnal signal. The continuous $5 \mathrm{~d}$ recording from 31 July to 5 August 1985 (Fig. 4) is of the first type. Again, there was a constant slow change in tilt, visible on both the longitudinal and transverse axes. The directions of tilt are such as to suggest a rise in the margin of the glacier relative to the center and a longitudinal steepening of the surface. Superimposed on this is a diurnal pattern on the transverse channel, again indicating a relative rise in the center of the glacier, with a maximum in the early afternoon. This peak usually extends from $\sim 11.00-$ $15.00 \mathrm{~h}$ and is sometimes characterized by rapid fluctuations. Note that the longitudinal channel does not show a similar diurnal pattern for this time period. Possible reasons for this are discussed below.

The recordings from $15-16$ and 29-30 July 1985 (Fig. 5) are of the second type. These records reveal three periods of rapid sinking in the center of the glacier and decreases in longitudinal slope. The latter are superimposed on a general increase in slope. As shown in Figure 5, each period is associated with a relatively heavy rainfall, and an accompanying high water-pressure event. The records are too short to give evidence of the long-term tilt changes, and that from 29 July begins after the high water-pressure event earlier in the day. In these two recordings, the time lag being between the rainfall and the response of the tiltmeters is less than $\sim 15-30 \mathrm{~min}$. This lag cannot be estimated more precisely, because the recordings from the automatic rain gauge have low time resolution.

In 1986, both tiltmeters were in operation. On the transverse axes, the average trends indicate general stability at site T86 (Fig. 6a) and a slow rise of the center of the glacier at site T86 (Fig. 6b). The longitudinal axes of both instruments suggest a decrease in longitudinal slope. As in 1985 , there is, on many days, a diurnal rise and fall of the center of the glacier superimposed on these trends. The amplitudes of the transverse and longitudinal diurnal peaks at site $\mathrm{T}_{86}$ (Fig. 6b) are roughly equal, suggesting that the locus of the rise was $\sim$ north-east of this site. The higher ampinutue of the peaks at site T86 suggests that it was probably closer to the locus. During this entire period the temperature was close to freezing on the glacier surface and new snow was accumulating periodically. The only melt that occurred was on south-facing mountain slopes, and in areas where the snow cover was so thin that radiation could penetrate it and be absorbed by underlying surficial debris or dirty ice. Thus, the flux of water into the glacier was low, though presumably not negligible.

In 1987, one tiltmeter was put into operation on 3 June at site T87. The recordings from it (Fig. 7) show a slow rise of the center of the glacier and a decrease in longitudinal slope during a $16 \mathrm{~d}$ period. The rise appears to have occurred in the area of the riegel down-glacier from the instrument. Note that the signal is relatively noisy during this period, with a slight increase in the amplitude towards the end. 

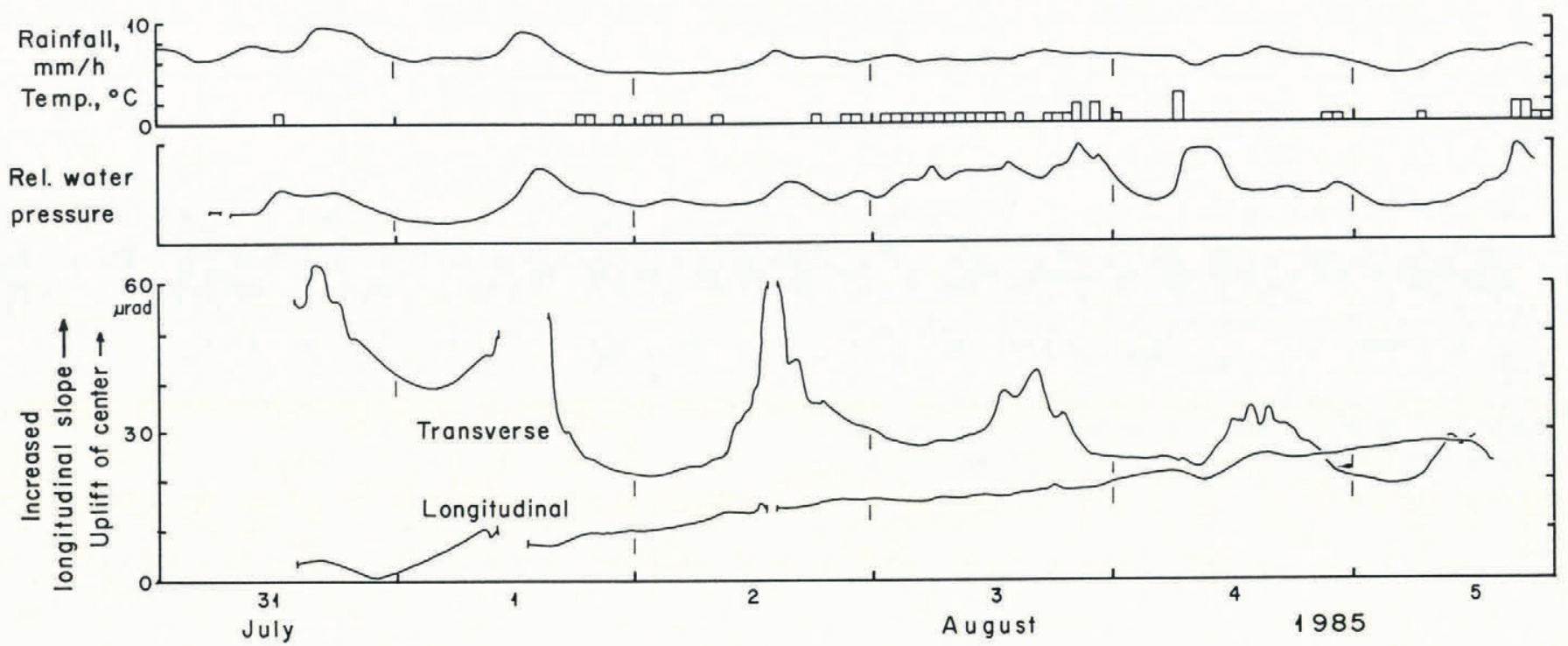

Fig. 4. Record from tiltmeter located at site T85 (Fig. 1) from 31 July to 5 August 1985. Temperature (curve), precipitation (bars), and water pressures were recorded in bore hole 85-4 (Fig. I).
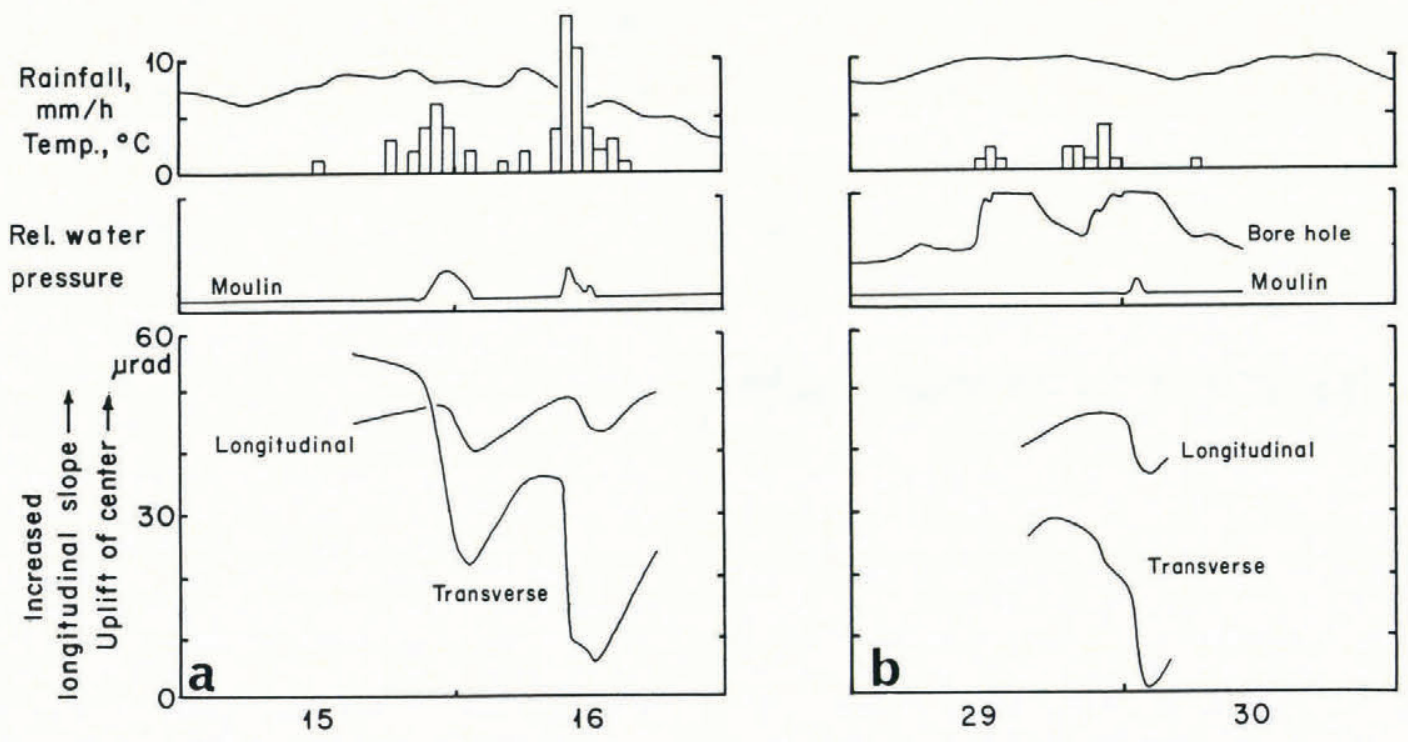

JuI y 1985

Fig. 5. Record from tiltmeter located site T85 from: (a) 15-16 July 1985; and (b) 29-30 July 1985. Relative water pressure in bore hole 85-4 and moulin 81-2 are shown at the top.

On 19 June, a drastic event took place in which the local north-east-south-west surface slope of the glacier decreased. This was followed by frequent high-amplitude fluctuations during the next $12 \mathrm{~h}$. If the disturbance were concentrated $100 \mathrm{~m}$ from the tiltmeter, its amplitude would have been $>0.05 \mathrm{~m}$ relative to any uplift at the meter. At noon the following day, this event came to an end with the same suddenness as it began, but a permanent deformation remained. The longitudinal component of this deformation was largest; there was also, however, a significant change in the transverse component. This event occurred at approximately the time when the snow-pack in the ablation area became saturated. The acceleration of stake net 23 (Fig. 1), which was being measured daily, occurred about $2 \mathrm{~d}$ earlier. This stake net was located $\sim 400 \mathrm{~m}$ down-glacier from the tiltmeter. If the two events are related, the disturbance was apparently propagating up-glacier at a rate of $\sim 200 \mathrm{~m} / \mathrm{d}$. T. Pfeffer (personal communication, October 1988) pointed out that as the disturbance lasted about $1 / 2 \mathrm{~d}$ it may have been about $100 \mathrm{~m}$ across. The sense of tilt at the meter is not such as to suggest a lowering of the surface down-glacier, as if a depression were migrating up-glacier. Thus, if the two events were related, the disturbance must have had another form. After this event, the signal becomes much less noisy, and long-term changes show a continued slow decrease in longitudinal slope and no significant trend in the transverse direction except for a slight relative lowering of the center of the glacier between 23 and 29 June.

On a smaller scale, there was, again, a diurnal variation between 9 and 15 July 1987 . The pattern resembles that seen in 1986 where both channels reacted simultaneously and similarly, indicating a disturbance north-east of the meter in the area of the riegel.

\section{DISCUSSION}

\section{Comparison of tilt records with other data}

We compared the tilt magnitudes and directions with data on vertical velocities of several stakes (Fig. 1) over the same time periods. In making these comparisons, we assumed that a segment of the glacier surface consisted of a rigid plane on which the tiltmeter and two or more stakes were located. Although the time periods chosen were generally $2-5 \mathrm{~d}$ long, the calculations did not show any consistent agreement between the tiltmeter records and stake movements. The values of surface tilting obtained by these two methods differed widely, both in magnitude and of ten, 

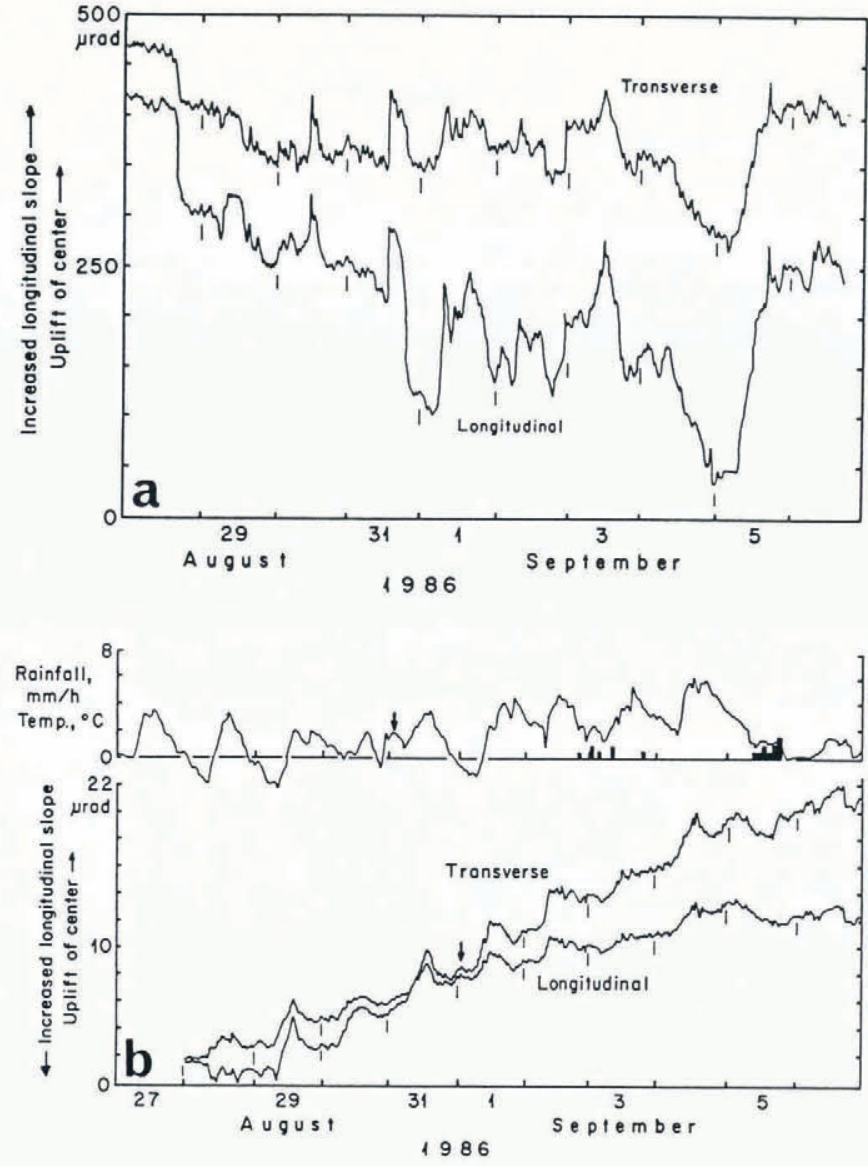

Fig. 6. Tiltmeter record from 28 August to 6 September 1986. a. Meter at site $T 86_{1}$. b. Meter at site $T 86_{2}$.

also, in direction of tilt. We therefore conclude that the tiltmeter measurements probably do not reflect what is happening over a larger area in the way assumed by the calculations. However, the inconsistencies could also be attributed to errors in the measured vertical velocities of the stakes or to the necessity of interpolating between measurements, in some cases, to get data for the appropriate time spans. The uncertainty in the difference in vertical velocity between two stakes obtained from surveys made $7 \mathrm{~d}$ apart is $\sim \pm 3 \mathrm{~mm} / \mathrm{d}$, so the uncertainty in the tilt rate between two stakes $100 \mathrm{~m}$ apart is $\sim \pm 30 \mu \mathrm{rad} / \mathrm{d}$, whereas tilt rates recorded by the tiltmeters are typically $2-20 \mu \mathrm{rad} / \mathrm{d}$. Alternatively, the inconsistencies could be due to the difference in location of the tiltmeters and the stakes.

On a broader scale, sinking of the center of a glacier relative to the margin is characteristic of the ablation area of valley glaciers; vertical velocities are upward, both in the center and near the margin but, due to the convex-upward transverse surface profile typical of the ablation area of glaciers, the vertical velocity near the margin is normally higher (Raymond, 1971). Stake surveys have shown that this is the long-term trend in this area on Storglaciären (Hooke and others, 1983, fig. 5). The pattern is complicated, however, by a marked uplift of Storglaciären, again demonstrated by stake surveys, that occurs annually during late July and August throughout the better part of the overdeepening (Hooke and others, 1983, 1989). Along the north side of the glacier in the overdeepening, the uplift in the center is large enough to reverse the normal pattern, so that during this period vertical velocities are actually higher at stake 2.45 than at stake $2 \mathrm{~N}$.

Taking these patterns into consideration, we again find little agreement between the tiltmeters and expectation. In 1984 and 1985, the relative sinking of the center recorded by the tiltmeters at locations T84 ${ }_{1}$ and T85 occurred at a time when the central uplift was in progress and at a place where tilting towards the northern margin is indicated by the stakes. However, in 1984 , the tiltmeter at $\mathrm{T} 84_{2}$, over the riegel, recorded a tilt towards the center line, which is the expected direction. In 1986, the tilting towards the margin recorded at site $\mathrm{T} 86_{2}$ occurred at a time and place where tilting towards the center is expected, and in 1987 a similar marginward tilt recorded at site T87 occurred at a time and place where the opposite trend is the rule.

There is more satisfactory agreement between the longitudinal tilting and the relative vertical velocities of stakes 3.35 and 1.35. During most of the year the vertical velocities of these stakes suggest a decrease in slope of this part of the glacier, which is consistent with the 1986 and 1987 tiltmeter data. However, during the summer uplift, the pattern can be reversed, as it was in late July 1984 and early July 1985. The July 1984 result is inconsistent with the tiltmeter results, but that from July 1985 is consistent with tiltmeter data obtained later in July of that year.

One could conclude from these results that we had our wires crossed or that the tiltmeters were providing unreliable data. However, careful checks have not found any indication that this has been the case. Moreover, the obvious systematic trends, diurnal oscillations, and correlations with meteorological events give us considerable confidence in the data. We conclude that the meters are sensing events over an area which is small compared to the distance between the meter and the stakes used for the above comparisons. It would be reasonable to assume, for example, that the meters sensed changes within an area having a diameter comparable to the ice thickness, $\sim 150 \mathrm{~m}$. This is consistent with the scale of the 19 June 1987 disturbance discussed above. The stakes used in the above comparisons generally lie well outside of this area.

\section{Diurnal variations}

The diurnal signal visible in the 1984 (Fig. 3), 1985 (Fig. 4), 1986 (Fig. 6), and 1987 (Fig. 7) records reflects an increase in height of the center of the glacier relative to the margin, as if the glacier were breathing. If the tiltmeters are sensing disturbances within an area with a diameter of $\sim 150 \mathrm{~m}$, the area affected by these events must extend from somewhat up-glacier of stake 3.35 down-glacier to the riegel. This is based on the observation that diurnal variations have been observed at all tiltmeter sites shown in Figure 1. The fact that the variations were not observed on the longitudinal axis at site T85, but were observed on this axis in 1986 at site T86, may indicate that the size of the affected area or that the response of the glacier varies either seasonally or inter-annually.

Let us first consider the possibility that these diurnal signals are related to deformation on a scale much less than that of the ice thickness. The tilt records might, for example, be a result of radiative warming of the tilt meters or thermal expansion of the ice. This seems unlikely, however, because the signals are different on different axes and because meters on opposite sides of the glacier indicate tilt in opposite directions. Furthermore, the meters are $1.5-2 \mathrm{~m}$ below the ice surface and there was a $0.05 \mathrm{~m}$ snow cover on the ice during the period of the 1986 record. Even in the absence of such snow, $99 \%$ of the solar radiation would be absorbed in the upper $1.9 \mathrm{~m}$ of ice (Paterson, 1972, p. 38). Finally, thermal expansion effects would be negligible. For example, as the temperature of the ice cannot rise above freezing, the maximum temperature variation at the ice surface during the period covered by the record in Figure $6 \mathrm{~b}$ is $\sim 3^{\circ} \mathrm{C}$. A $3^{\circ} \mathrm{C}$ oscillation in temperature with a $24 \mathrm{~h}$ period would be attenuated to $<0.02{ }^{\circ} \mathrm{C}$ at a depth of $1.0 \mathrm{~m}$. The average temperature change over this depth range would be $\sim 0.4^{\circ} \mathrm{C}$. With a coefficient of thermal expansion of $\sim 5 \times 10^{-5}$, this would cause a strain of $\sim 2 \times 10^{-5}$. Exactly how this might be transformed into tilt probably depends on the locations of crevasses that could relieve the strain. However, to yield a $4 \mu \mathrm{rad}$ tilt as in Figure $6 \mathrm{~b}$, differential uplift of this amount would have to occur over a horizontal distance of $5 \mathrm{~m}$, whereas the nearest crevasses were at least $50 \mathrm{~m}$ away. We, therefore, conclude that the diurnal signals do, in fact, represent relative uplift of the center of the glacier.

Such uplift could be attributed either to an increase in longitudinal compression or to uplift of the glacier by increased subglacial water pressure. The peaks in the tilt records are generally associated with peaks in water pressure in bore holes up-glacier (Fig. 7) or down-glacier (Fig. 4) from the tiltmeters, which, however, they lag or lead, 


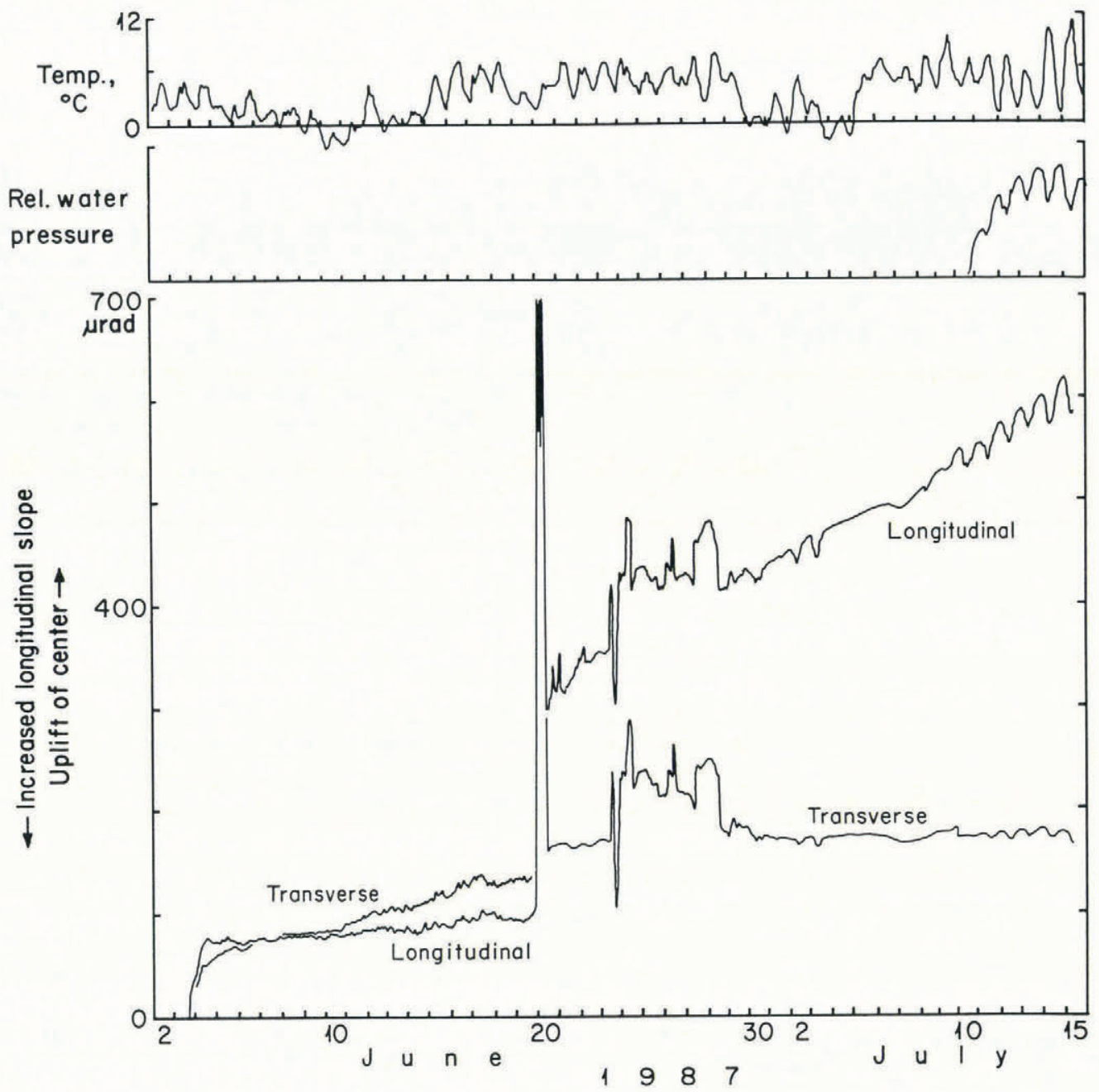

Fig. 7. Record from tiltmeter located at site T87 from 3 June to 14 July 1987. Water-pressure variations, recorded in bore hole 87-3 (Fig. 1), were equivalent to changes in water level of only 1-2 $\mathrm{m}$. They might be due to changes in water input to the hole at the surface, but the lag between the temperature peaks and the water-pressure peaks would then be much less.

respectively, by a few hours. In contrast, the strain measurements from 1983 (Fig. 2) suggest that the periods of increasing water pressure are associated with tensile strains. If this is generally true, and if strain measurements are representative of the state of strain about $200 \mathrm{~m}$ further upglacier, the uplift of the glacier surface cannot be due to increased compression. Thus, we suggest that the uplift is, in fact, due to the increase in water pressure alone.

Attributing the uplift to increase in water pressure would seem unlikely if the water pressure were not already high in this area. However, as noted above, water pressures in this area are apparently close to overburden pressure most of the summer, a conclusion substantiated by apparent widespread reduction in basal drag indicated by forcebalance calculations and bore-hole deformation measurements (Hooke and others, 1987, 1989; paper in preparation by V. Pohjola and R.LeB. Hooke).

If the above line of reasoning is valid, we need to explain the lack of correspondence between the timing of the maximum uplift and the maximum water pressure in Figures 4 and 7 . This we attribute to down-glacier movement of a wave of high pressure that was initiated when water entered the glacier by way of the crevassed zone just above the equilibrium line (Fig. 1) the preceding day. (Down-glacier from the equilibrium line, most melt water collects in streams and does not enter the glacier until it reaches the crevassed area over the riegel.) In 1987 (Fig. 7), the water-pressure peaks in bore hole 87-3 lagged the temperature peaks by $\sim 9 \mathrm{~h}$ and led the tilt peaks by 4-5 h. In 1985 (Fig. 4), the tilt peaks led the waterpressure peaks in holes down-glacier from the tiltmeters by $\sim 1.5-4.5 \mathrm{~h}$. (The latter water-pressure maxima, when they occur in the mid-afternoon may, of course, be due, at least in part, to melt water entering the glacier over the riegel.)
These figures suggest a wave speed of $\sim 55 \pm 10 \mathrm{~m} \mathrm{~h}^{-1}$. As the tilt peaks last $\sim 8 \mathrm{~h}$, the wavelength of the disturbance is $\sim 400 \mathrm{~m}$.

Support for this model comes from comparing the shapes of the 1986 tilt peaks with those of the temperature peaks a day earlier (Fig. 6b). In particular, note that the warm spell about midnight on 30-31 August is reflected in the tilt pattern $\sim 24 \mathrm{~h}$ later (see arrows).

It is also noteworthy that, during periods of precipitation on the glacier, the diurnal pattern recorded by the tiltmeters is subdued relative to the temperature curve the preceding day (Fig. 6b). 28 August and 3 September, for example, were rainy days and also days with low diurnal tilt peaks, and on 5 September, a day of heavy rain, there was a trough rather than a peak in the tilt curve. Rainwater entering the glacier in moulins over the riegel may have caused an acceleration of the lower part of the glacier and a corresponding increase in extension somewhat up-glacier from the riegel, thus cancelling the uplift signal.

To investigate the relation between the temperature and the tilt response, a cross-correlation was made (Fig. 8). The longer-term trends in both the tilt and the temperature curves were first removed by using, as input values, the deviations of the curves from best-fit straight lines. We also assumed that tilt lags the temperature, and therefore we disregarded correlations showing the converse. The results (Fig. 8) suggest a $21-22 \mathrm{~h}$ time lag between a temperature peak and the corresponding tilt response, although there is also, as with any such cyclic phenomenon, a good correlation with no lag.

We do not think that the correlation with zero time lag is correct. As discussed above, thermal effects do not appear to be large enough to produce the observed signal. A rapid transfer of a water-pressure signal from the 


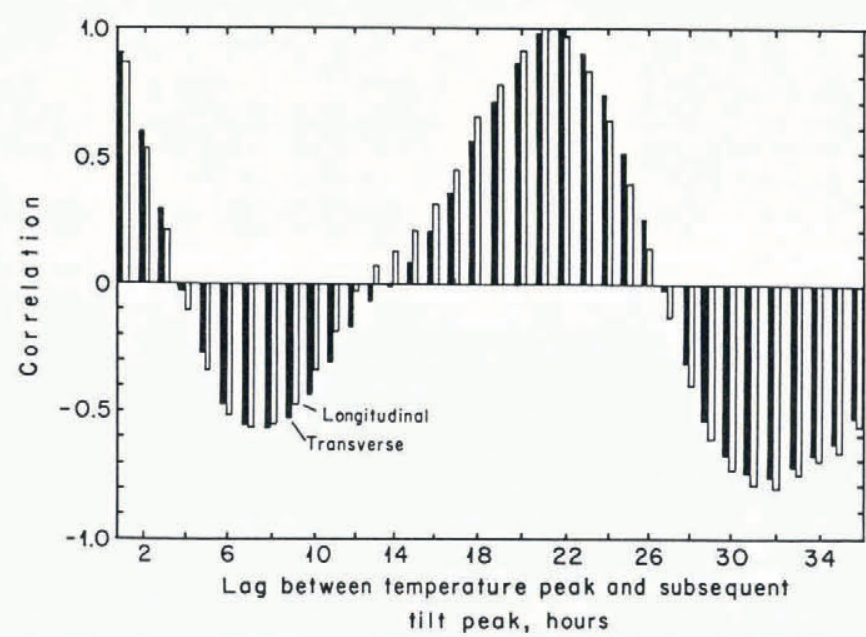

Fig. 8. Cross-correlations of 1986 tiltmeter record from site $\mathrm{T}_{86_{2}}$ with temperature.

crevassed area above the equilibrium line to the tiltmeters also seems unlikely. This could occur, of course, if increased water pressure in this area resulted in a hydraulic-jacking effect, pushing the ice down-glacier, and if the ice were free to slide readily between this area and the site of the uplift. Such uplift, however, would then be the result of compressive strain and, as noted, the strain-meter results suggest tension during this time of day. Furthermore, force-balance calculations (Hooke and others, 1989) suggest that there is still considerable drag at the bed during high water-pressure events, so such sliding is probably unreasonable.

If there is a propagating wave in the ice surface, the tiltmeter records should provide some additional evidence for this. For example, on the longitudinal axes, a propagating wave should result in a down-glacier tilt followed by an up-glacier tilt and then a return to the original orientation. Figure 9 illustrates this response. The curves in

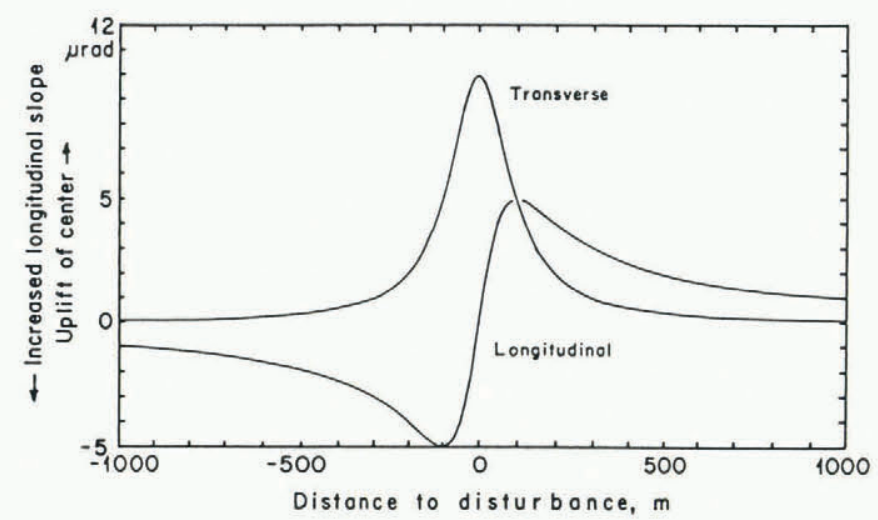

Fig. 9. Theoretical response of a tiltmeter to a disturbance that passes down-glacier $100 \mathrm{~m}$ from the tiltmeter and raises the surface $0.01 \mathrm{~m}$.

this figure were calculated from the change in slope of a straight line between a tiltmeter and a $0.01 \mathrm{~m}$ high disturbance that traveled down-glacier and passed the tiltmeter at a distance of $100 \mathrm{~m}$. The pattern on the longitudinal axis is similar to that shown by the longitudinal axis in Figure 5a (discussed further below). Such patterns are not found in the diurnal signals of Figure 6. Therefore, it appears that, if waves were propagating down-glacier, they were not large enough or close enough to site $\mathrm{T} 86_{2}$ for the tiltmeter there to record their passage. However, the 1984 record from the tiltmeter at site $\mathrm{T}_{24}$ (Fig. 3) does resemble the curves in Figure 9 to the extent in that the peak in transverse tilt occurs during the period of decreasing longitudinal slope.

A propagating wave in the ice surface should also affect up-glacier tiltmeters before those situated further down-glacier. In 1986 (Fig. 6a, b), no such time lag is present. However, in 1984, there was a phase shift between the longitudinal tilt signals recorded by the up-glacier and down-glacier instruments. The records are too short to be sure of the sign of the phase shift, but an argument can be made for the up-glacier signal leading the down-glacier one by $\sim 18 \mathrm{~h}$, suggesting a wave speed, in this instance, of only $20 \mathrm{~m} / \mathrm{h}$. (As these disturbances, at least in the longitudinal record, appear to last nearly a full day, the wavelength of the disturbance would again be $400-500 \mathrm{~m}$.)

In conclusion, we suggest that waves of increased water pressure do propagate down-glacier, but they do not become large enough to lift the glacier surface until they get close to the riegel. There, due possibly to a focusing effect related to the bed topography (Fig. 1), possibly to some sort of constriction of the drainage system as is implied by the large change in water pressure across the riegel, or possibly simply to the reduction in glacier thickness, they become large enough to cause an uplift of the surface. In late August 1986, we suggest that the wave passed site $\mathrm{T} 86_{2}$ before it grew sufficiently large to affect the surface there, whereas in late July 1984 it was already large enough when it passed site $\mathrm{T} 84_{1}$ to lift the surface.

\section{"Direct-response" patterns}

The records discussed above deal with variations which occur during periods when melt was the main source of water input to the glacier. The two records from days with heavy rainfalls (Fig. 5) show quite different patterns. Melt rates are typically $\sim 2 \mathrm{~mm} \mathrm{~h}^{-1}$, whereas the rainfalls delivered up to $12 \mathrm{~mm} \mathrm{~h}^{-1}$, so it is not surprising that the responses were different. As noted, these records reveal a sinking in the center of the glacier and a rapid decrease and subsequent slower increase in longitudinal slope. We infer that the rainwater enters the glacier in the crevassed region over the riegel and therefore has an immediate effect on water pressures down-glacier from the riegel. The high water pressures here cause acceleration of the lower part of the glacier, and this is accompanied by longitudinal stretching in the central part above the riegel and south of the meter (located at T85). The transverse axis is affected before the longitudinal axis, suggesting an initial decrease in slope, so it appears that the zone of depression arising from extension was initially concentrated near the center line. The subsequent decrease in longitudinal slope may indicate that, up-glacier from the tiltmeter, the zone of depression subsequently spread laterally. The longitudinal slope then returned to its previous value, but there was "permanent" sinking of the central part of the glacier.

On 5 September 1986, the record from site $\mathrm{T}_{86}$ (Fig. 6b), on the other side of the glacier and farther upglacier from the riegel, shows a similar sinking of the central part of the glacier associated with rainfall.

\section{CONCLUSIONS}

Sensitive strain and tilt measurements on Storglaciären have revealed unexpected details of the dynamic reaction of the glacier to water input. Both long-term and short-term changes in tilt occur. The former usually suggest a rise of the center of the glacier and a decrease in longitudinal slope during the summer, but in late July 1984 the center was being depressed, and in early August 1985 both trends were in opposite directions. These trends are of ten inconsistent with expectation or with measurements on stakes, which leads us to believe that the tiltmeters sense trends occurring over areas on the scale of the ice thickness rather than more "regional" trends on the scale, say, of the glacier half-width.

The short-term variations show a complicated delayedresponse pattern, apparently related to melt-water input, and also a direct-response pattern during rainstorms. Critical to interpretation of the measurements is recognition of the role that crevasses play in controlling the locations of water input. Crevasses are concentrated in two areas, one near the equilibrium line and the other over the riegel near the middle of the ablation area. The obstructions in the bed topography which cause this crevassing appear to be two beds of resistant rock that dip up-glacier. Diurnal variations in the rate of water input to the glacier by way of the 
crevasse field near the equilibrium line appear to generate waves of water pressure that travel down-glacier at speeds of $\sim 20-60 \mathrm{~m} \mathrm{~h}^{-1}$. Focusing of these waves by the bed topography then results in local uplift. Similar variations in water input by way of the crevasse field over the riegel result in alternating extension and compression just up-glacier from the riegel. Higher rates of water input over the riegel during rainstorms produce more extreme reactions.

Such localization of water input in areas of crevassing may have significant geomorphic implications. Crevasses are characteristic of areas where glacier beds are convex upward, with relatively steep down-glacier-facing slopes. Frequent acceleration and deceleration of the ice downglacier from such slopes may result in powerful plucking action, as suggested by Röthlisberger and Iken (1981). Such plucking may, in fact, maintain the slope steepness. Hence, riegels may owe their existence to a positive feed-back process whereby a local steepening of the bed results in crevassing, which in turn leads to more intensive plucking that accentuates the steepening. Although in the case of Storglaciären the initial perturbation may have been related to differences in resistance of the bedrock, this may not be true of riegels beneath other glaciers. Cirque headwalls may owe their steepness to similar plucking action resulting from variations in water input through a bergschrund.

In conclusion, it appears that even relatively small glaciers like Storglaciären are not as tranquil as one might think. Instead, we can see complex patterns of short-term variations in the dynamics of the glacier.

\section{ACKNOWLEDGEMENTS}

It is a pleasure to thank $\mathbf{M}$. Walford and $\mathbf{M}$. Kennett for assistance with electronics. N. Iverson collected the data from 1984. We also appreciate the help of numerous field assistants through the years. The paper benefited from critical reviews of $\mathrm{K}$. Echelmeyer and T. Pfeffer.

The tiltmeters were designed by $\mathrm{J}$. Westphal and built by M. Carr. They were purchased with funds generously provided by the Wallenberg Foundation of Stockholm. Financial support for other aspects of the study was provided by the Swedish Natural Sciences Research Council, the U.S. National Science Foundation, the Swedish Society for Anthropology and Geography, and the Ahlmann, Carl Mannerfelts and Axel Lagrelius' funds of Sweden.

\section{REFERENCES}

Björnsson, H. 1981. Radio-echo sounding maps of Storglaciären, Isfallsglaciären and Rabots glaciär. Geogr. Ann., 63(3-4), 225-231.
Brand, G., V. Pohjola, and R.LeB. Hooke. 1987. Evidence for a till layer beneath Storglaciären, Sweden based on electrical resistivity measurements. J. Glaciol., 33(115), 311-314.

Holmlund, P. and R.LeB. Hooke. 1983. High waterpressure events in moulins, Storglaciären, Sweden. Geogr. Ann., 65A (1-2), 19-25.

Hooke, R.LeB., J. Brzozowski, and C. Bronge. 1983. Seasonal variations in surface velocity, Storglaciären, Sweden. Geogr. Ann., 65A(3-4), 263-277.

Hooke, R.LeB., P. Holmlund, and N.R. Iverson. 1987. Extrusion flow demonstrated by bore-hole deformation measurements over a riegel, Storglaciären, Sweden. J. Glaciol., 33(113), 72-78.

Hooke, R.LeB., S.B. Miller, and J. Kohler. 1988. Character of the englacial and subglacial drainage system in the upper part of the ablation area of Storglaciären, Sweden. J. Glaciol., 34(117), 228-231.

Hooke, R.LeB., P. Calla, P. Holmlund, M. Nilsson, and A. Stroeven. 1989. A 3 year record of seasonal variations in surface velocity, Storglaciären, Sweden. J. Glaciol., 35 (120), 235-247.

Kamb, B. and H. Engelhardt. 1987. Waves of accelerated motion in a glacier approaching surge: the mini-surges of Variegated Glacier, Alaska, U.S.A. J. Glaciol., 33(113), 27-46.

Östling, M. and R.LeB. Hooke. 1986. Water storage in Storglaciären, Kebnekaise, Sweden. Geogr. Ann., 68A(4), 279-290.

Paterson, W.S.B. 1972. Temperature distribution in the upper layers of the ablation area of Athabasca Glacier, Alberta, Canada. J. Glaciol., 11(61), 31-41.

Raymond, C.F. 1971. Flow in a transverse section of Athabasca Glacier, Alberta, Canada. J. Glaciol., 10(58), 55-84.

Röthlisberger, H. and A. Iken. 1981. Plucking as an effect of water-pressure variations at the glacier bed. Ann. Glaciol., 2, 57-62.

Schytt, V. 1959. The glaciers of the Kebnekajse-massif. Geogr. Ann., 41A(4), 213-227.

Schytt, V. 1966. Notes on glaciological activities in Kebnekaise, Sweden during 1965. Geogr. Ann., 48A(1), 43-50.

Schytt, V. 1968. Notes on glaciological activities in Kebnekaise, Sweden during 1966 and 1967. Geogr. Ann., 50A(2), 111-20.

Seaberg, S.Z., J.Z. Seaberg, R.LeB. Hooke, and D.W Wiberg. 1988. Character of the englacial and subglacial drainage system in the lower part of the ablation area of Storglaciären, Sweden, as revealed by dye-trace studies. $J$. Glaciol., 34(117), 217-227. 